\title{
DOMINANTLY INHERITED DRUSEN REPRESENT MORE THAN ONE DISORDER: A HISTORICAL REVIEW
}

\author{
BERTRAND PIGUET, ROBERT HAIMOVICI and ALAN C. BIRD \\ London
}

\begin{abstract}
SUMMARY
Hutchinson-Tay choroiditis, Holthouse-Batten chorioretinitis, Doyne's honeycomb familial choroiditis and Malattia levantinese are various names which have been used to denote dominantly inherited drusen. Whether these represent one or more than one disorder remains unclear because of the quality of the illustrations and incomplete information in some of the original articles. The early descriptions of these various conditions have been reviewed. Evidence is presented that Doyne's honeycomb familial choroiditis and Malattia levantinese are disorders which can be distinguished from each other by clinical criteria.
\end{abstract}

Drusen of Bruch's membrane were first demonstrated microscopically by Wedl in $1854,{ }^{1}$ and clinically by Donders in $1855 .^{2}$ Since that time, drusen have been noted by several authors to occur in families as a dominantly inherited disorder. Familial and non-familial drusen have been considered to have a similar fundus appearance, making a distinction between the two difficult on clinical grounds. The published literature on inherited drusen describes dominant inheritance almost exclusively. $^{3-5}$

Dominantly inherited drusen have been known by several different names in the past. These have included Hutchinson-Tay choroiditis, ${ }^{6}$ guttata choroiditis, ${ }^{7}$ Holthouse-Batten superficial chorioretinitis, ${ }^{8}$ Doyne's honeycomb retinal degeneration, ${ }^{9}$ family choroiditis, ${ }^{10}$ Malattia levantinese ${ }^{11}$ and crystalline retinal degeneration. ${ }^{12}$ Although the patients described differed with regard to the size, shape and distribution of drusen, it has been considered by

From: Department of Clinical Ophthalmology, Institute of Ophthalmology, Moorfields Eye Hospital, London, UK.

Correspondence to: Alan C. Bird, MD, Professorial Unit, Moorfields Eye Hospital, City Road, London EC1V 2PD, UK. many that these clinical entities constitute a single condition. ${ }^{4,13,14}$ However, there are incomplete data regarding the natural history, histopathological, electrophysiological and psychophysical findings of these disorders to substantiate this belief. The lack of illustrations in the original descriptions, and the confusion which has followed in the ophthalmic literature, have tended to obscure the specific characteristics which might allow these syndromes to be distinguished from one another.

In this paper, we review the descriptions of the clinical characteristics of each of these various conditions in order to identify whether or not there may be more than one nosological entity within this disease complex.

\section{HUTCHINSON-TAY GUTTATE CHOROIDITIS}

In 1875, Jonathan Hutchinson and Warren Tay published a report of 10 cases of 'symmetrical central chorioretinal disease occurring in senile persons'. ${ }^{6}$ Three of these reported cases were sisters, aged 60,50 and 40 years. The family history revealed that their father and one of his brothers also had poor sight, of unknown cause. Ophthalmoscopically, there were whitish spots in the macula and peripapillary region, small and round in shape, sometimes coalescing to give larger plaques. The three sisters had visual loss and one of them had a 'large central windmill-sail-like lesion' that could have been a subretinal fibrovascular scar as a result of choroidal neovascularisation. The other cases reported represented a heterogeneous collection of other conditions.

The absence of illustrations, and the variety of disorders presented in the original paper, make this entity particularly difficult to characterise with more accuracy, and explain the confusion that followed the initial publication. Two isolated cases with no family 


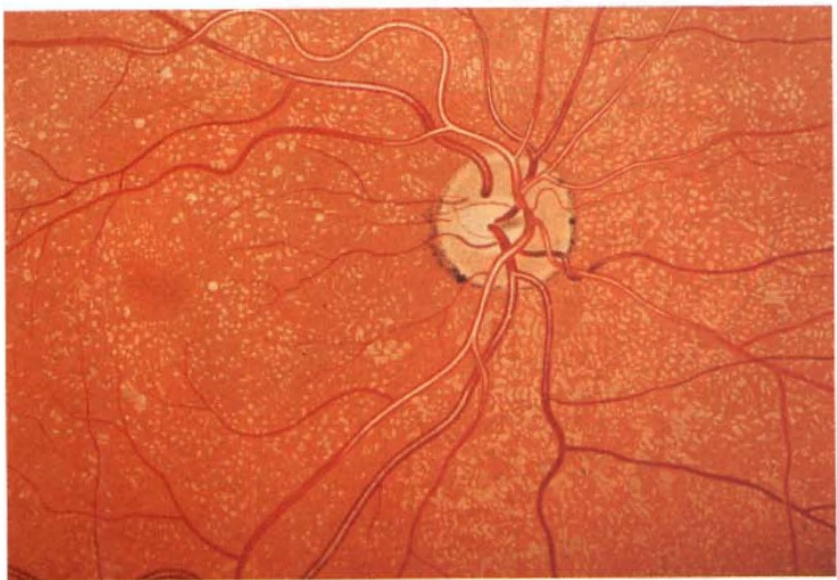

Fig. 1. Illustration of Dr Juler's case of Hutchinson-Tay guttata choroiditis. (Reprinted with permission from Eye.)

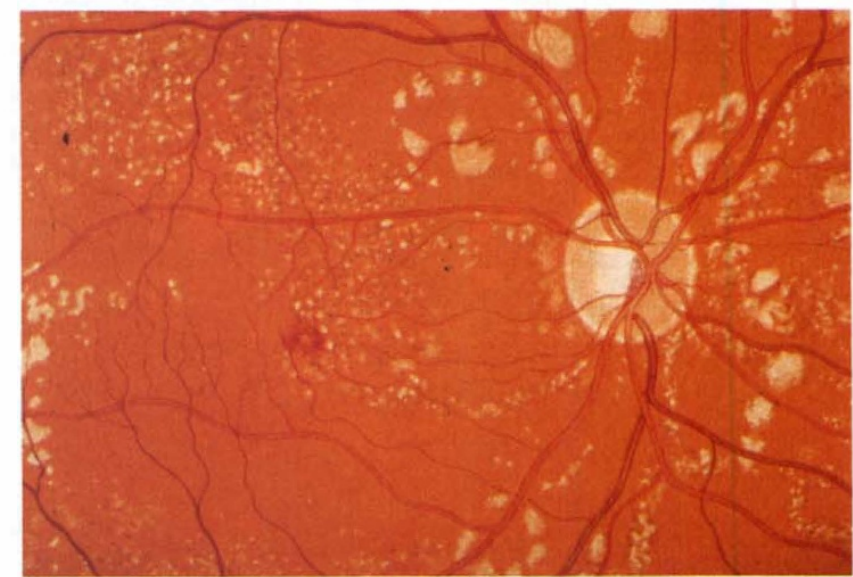

Fig. 2. Illustration of Dr Clarke's case of Hutchinson-Tay guttata choroiditis. (Reprinted with permission from the Journal of the Royal Society of Medicine.)

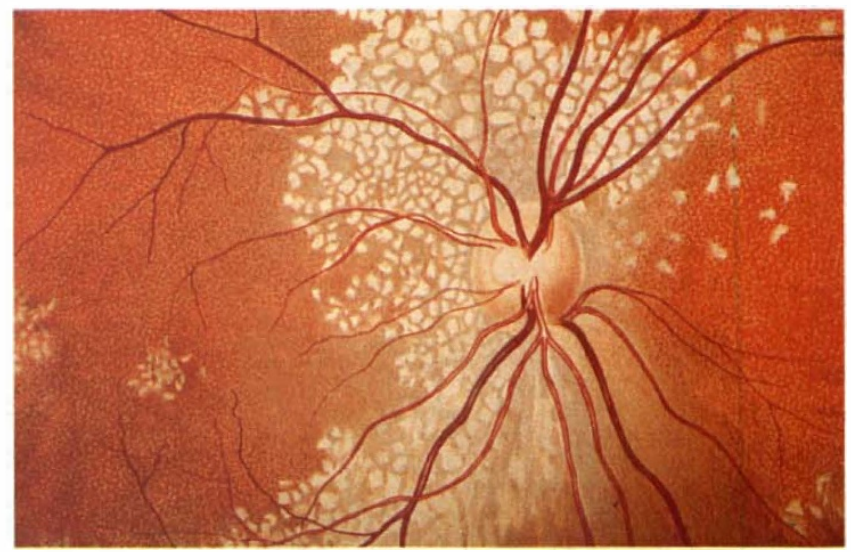

Fig. 4. Illustration of Dr Bickerton's case of 'a peculiar form of affection of the choroid'. (Reprinted with permission from Eye.)
Fig. 3. Illustration of Batten's case of 'superficial choroido-retinitis of peculiar form and doubtful causation'.

oido-retinitis of peculiar form and
(Reprinted with permission from Eye.)

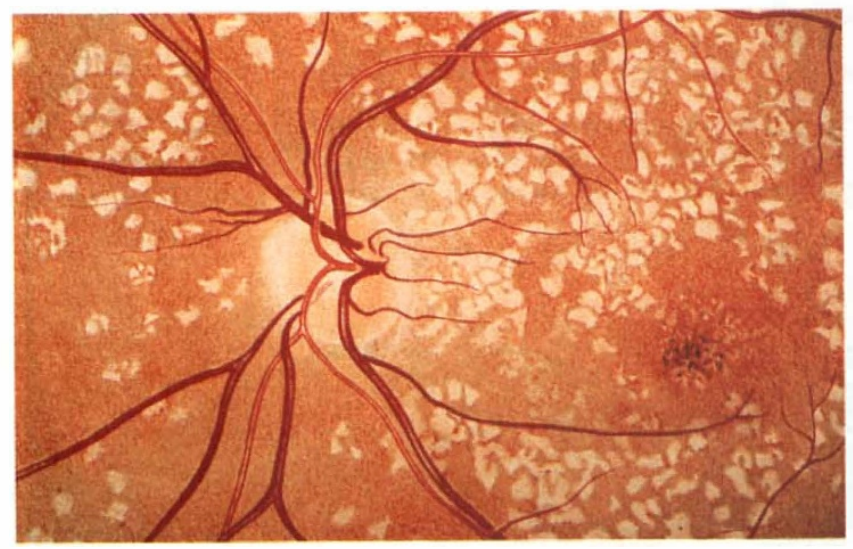

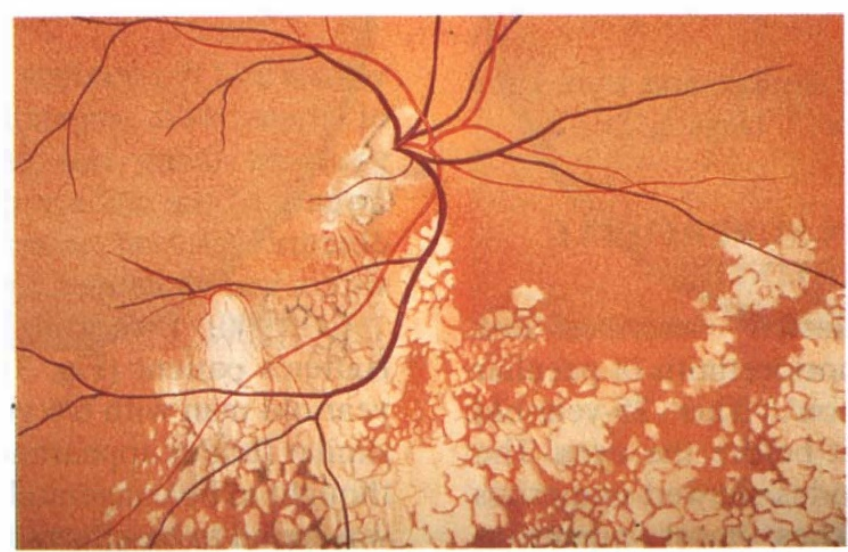

Fig. 5. Unusual unilateral form of choroiditis as described by Mr Blair. (Reprinted with permission from Eye.) 


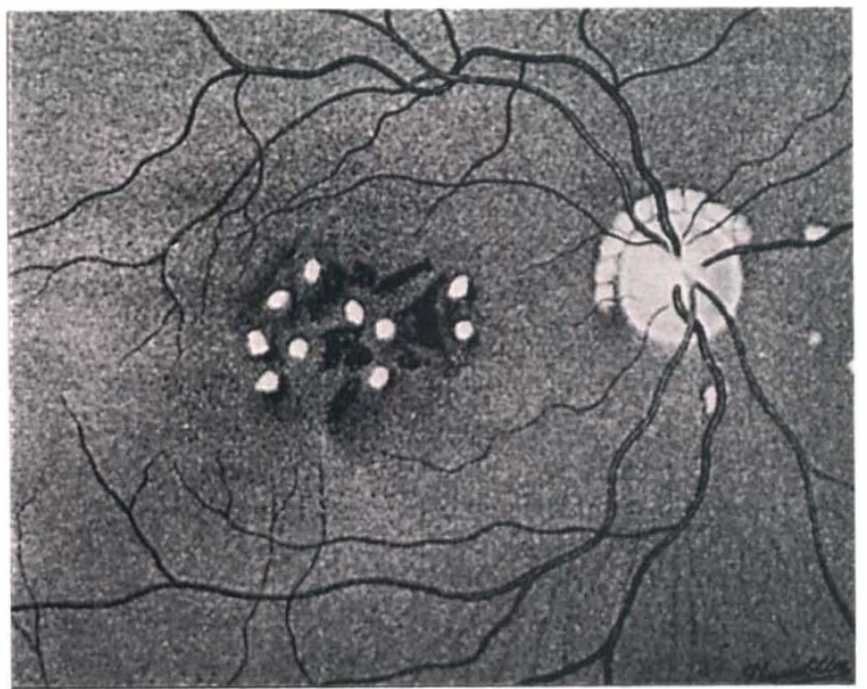

Fig. 6. Illustration of an early stage of Doyne's honeycomb choroiditis (Tree's case). (Reprinted with permission of the British Medical Association.)

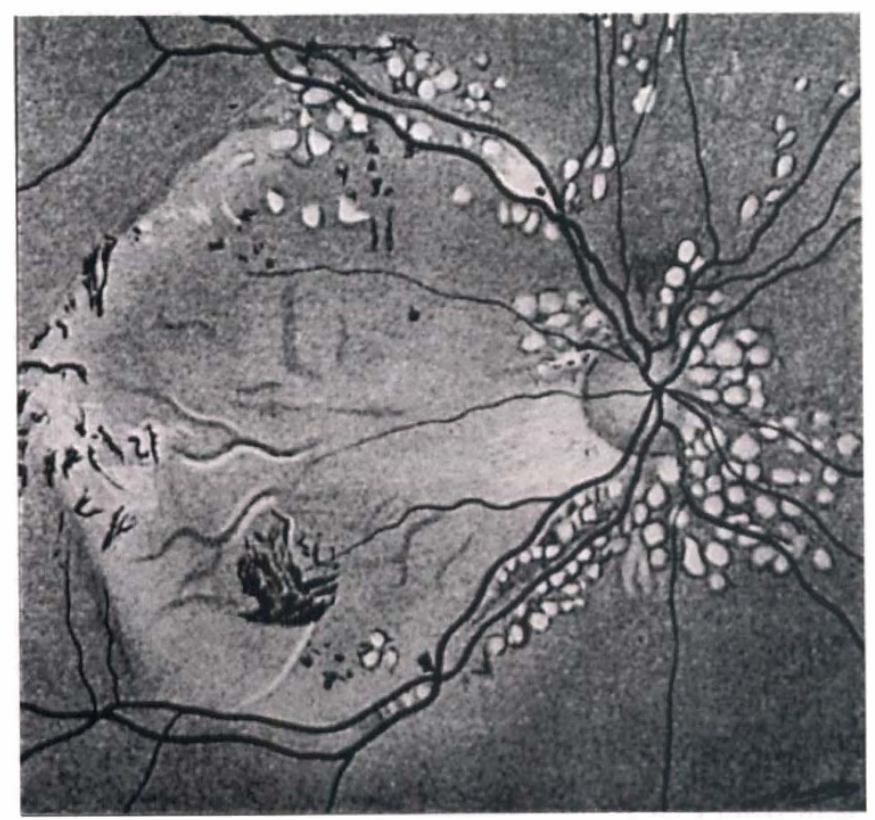

Fig. 8. Illustration of Doyne's honeycomb choroiditis from Tree's article showing extensive central atrophy. (Reprinted with permission of the British Medical Association.)

history were considered to be similar, and were later illustrated by Juler ${ }^{7}$ and Clarke ${ }^{15}$ (Figs. 1,2).

\section{HOLTHOUSE-BATTEN SUPERFICIAL CHOROIDO-RETINITIS}

In 1897, Holthouse and Batten $^{8}$ described one isolated case of 'superficial chorioretinitis of peculiar form and doubtful causation'. This 25-year-old woman complained of a mist before the eyes. The visual acuity was $6 / 9$. The fundus showed numerous small, scattered white patches, most numerous around the macula and optic disc. The largest patches were four times the diameter of the largest

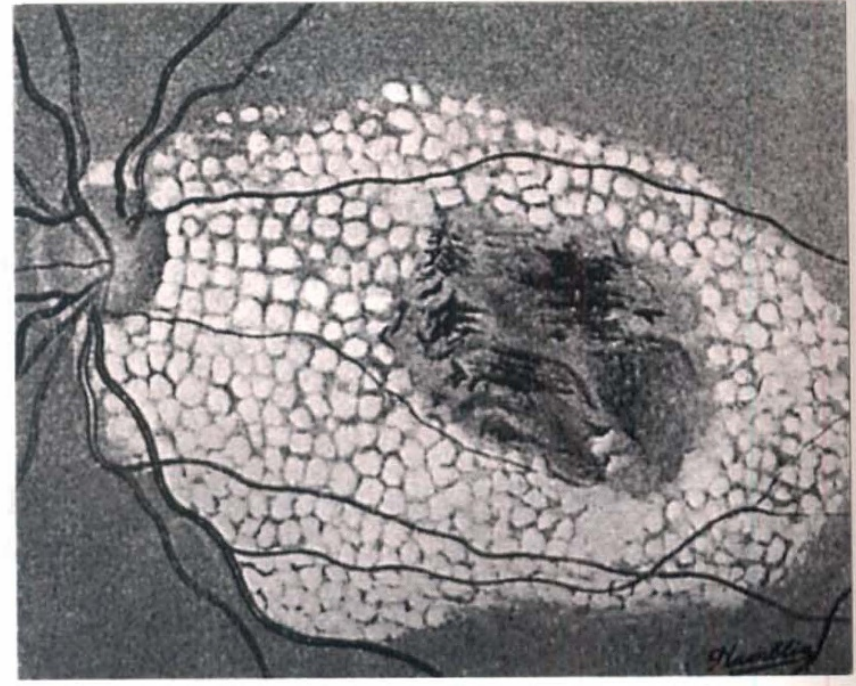

Fig. 7. Illustration of Doyne's honeycomb choroiditis from Tree's article showing atrophic changes surrounded by deposits. (Reprinted with permission of the British Medical Association.)

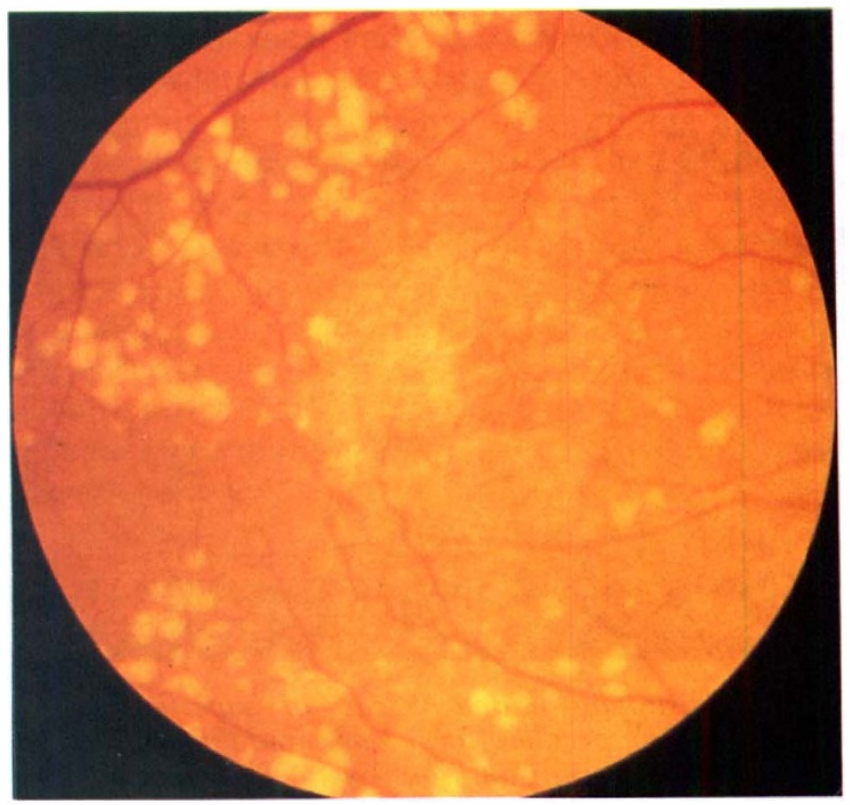

Fig. 9. Doyne's honeycomb 'choroiditis' showing extensive drusen with early atrophy centrally.

vessels and the smallest, minute circular points. None of them were pigmented. The patient was the youngest living out of a family of 24 children. Twenty of the siblings died at a young age of some obscure cerebral complaint. One of the patient's sisters was examined and found to be normal.

In 1900, Bickerton ${ }^{16}$ published a drawing of Batten's patient (Fig. 3) and described another 29year-old man with $6 / 6$ vision in both eyes and a very similar fundus appearance (Fig. 4). The disorder was thought to be congenital but no other family member was found to be affected. A last case was reported by Blair in $1901^{17}$ but appears to represent a different disorder. This 42-year-old woman had deposits which 


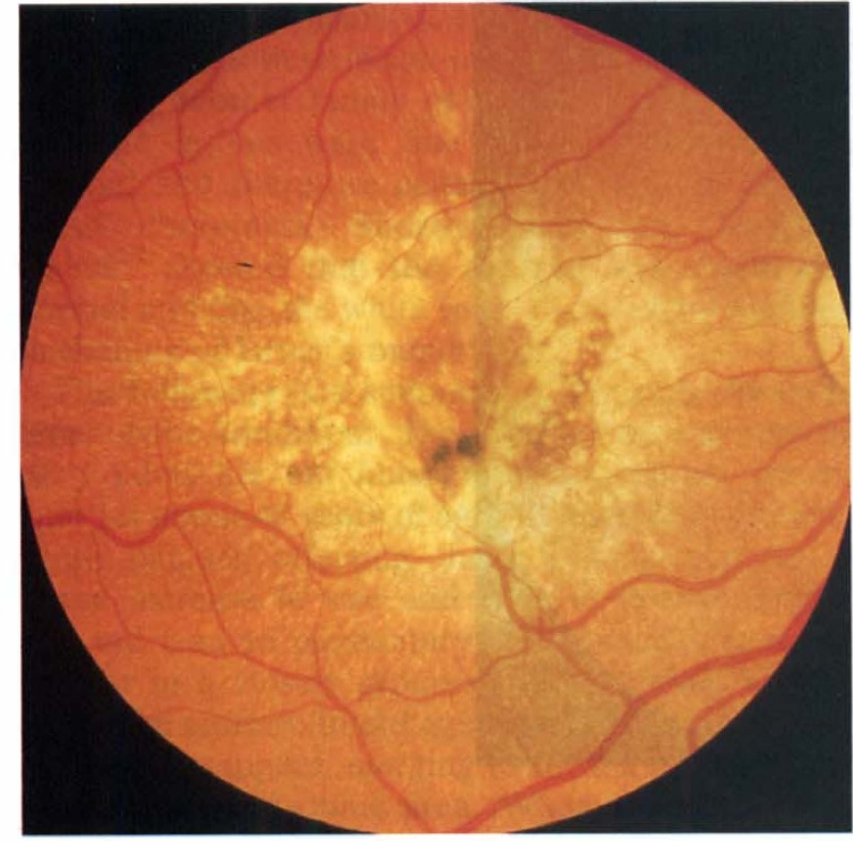

(a)

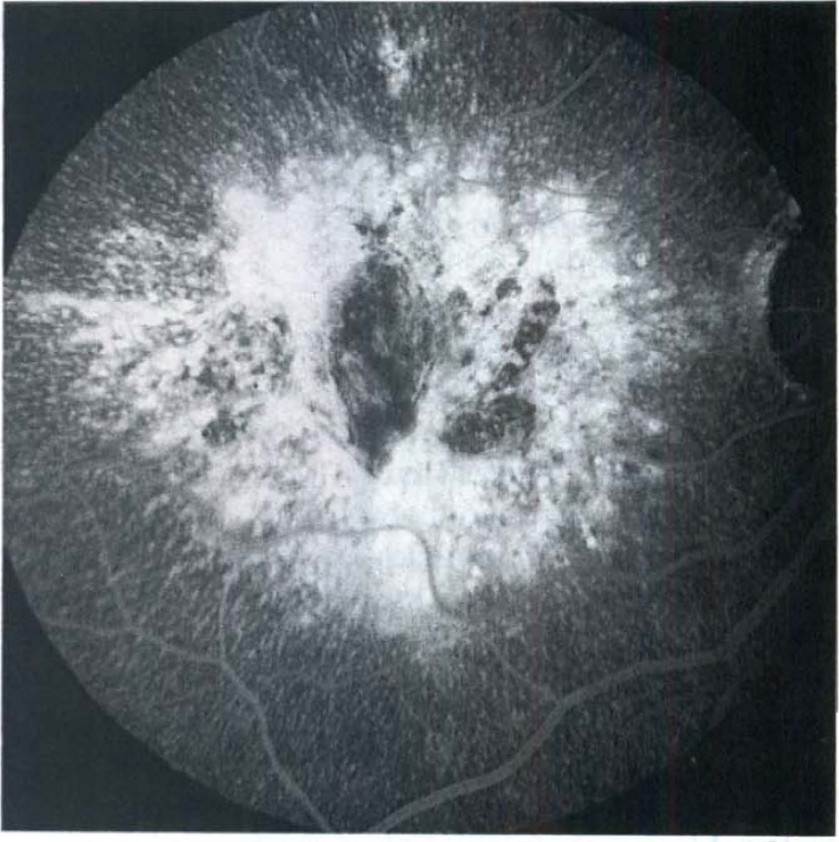

(b)

Fig. 10. Malattia levantinese. (a) Diffuse central deposits with radiate deposits in the periphery. Prominent pigment epithelial changes are seen. (b) The macular deposits are hyperfluorescent on fluorescein angiography. The blocked fluorescence centrally may be explained by pigment epithelial hyperplasia.

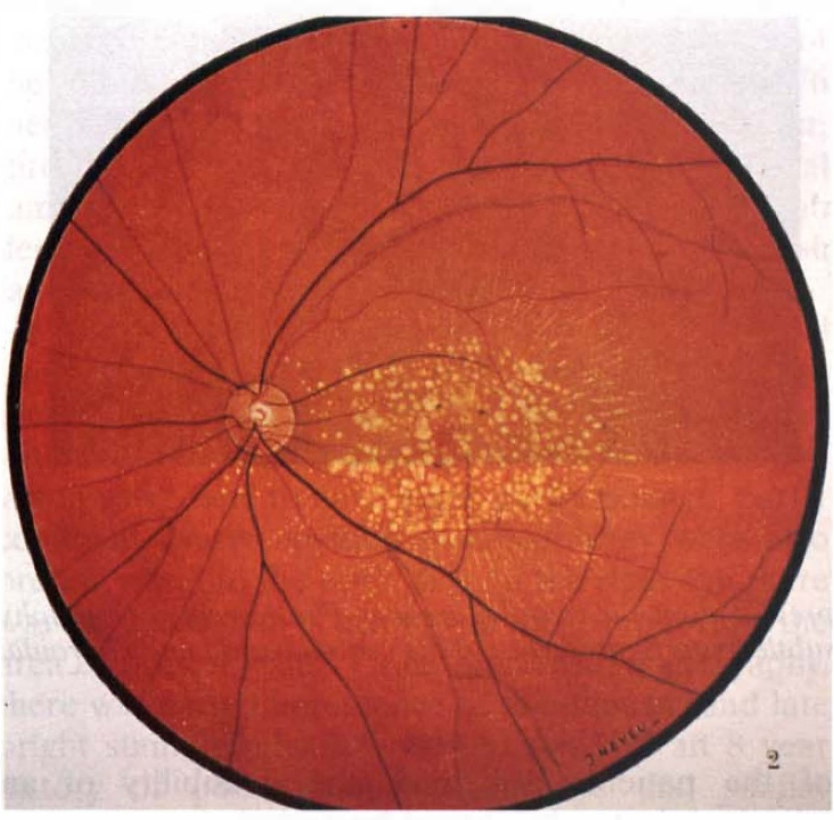

(a)

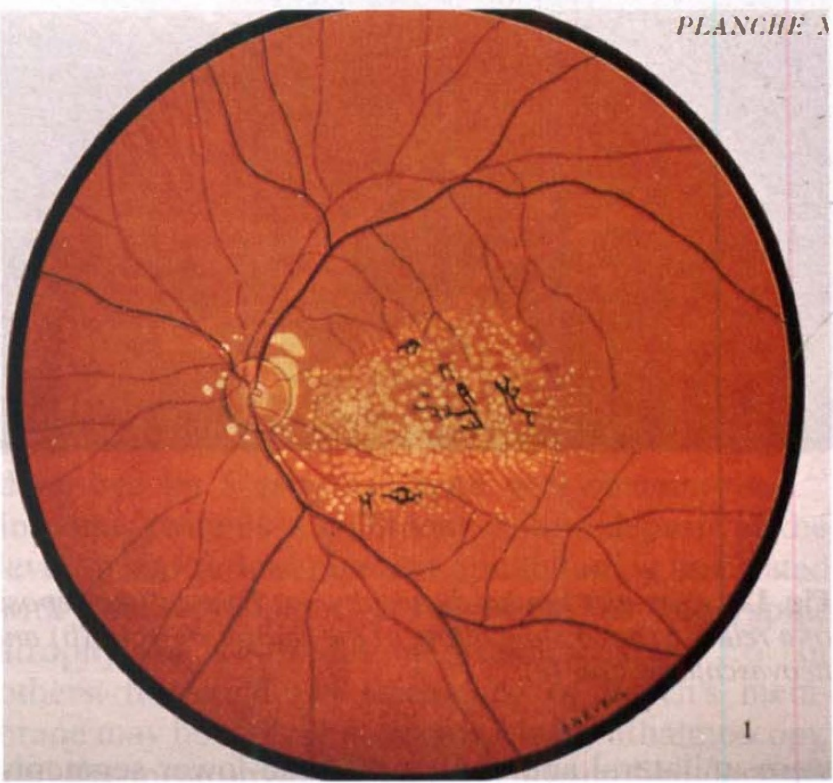

(b)

Fig. 11. Illustration of Malattia levantinese. (a) Diffuse involvement of the macula and peripapillary region with linear radiate yellow deposits in the periphery. (b) Well-developed form with secondary pigmentation and central atrophy. (Reprinted with permission of Sociétés d'Ophtalmologie de France.) 


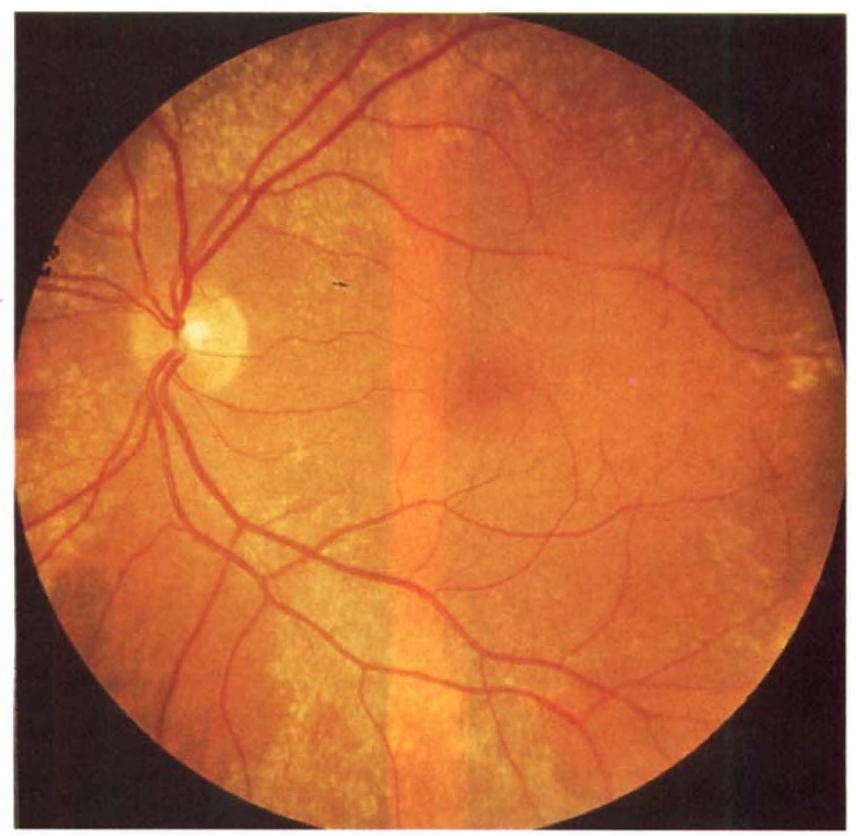

(a)

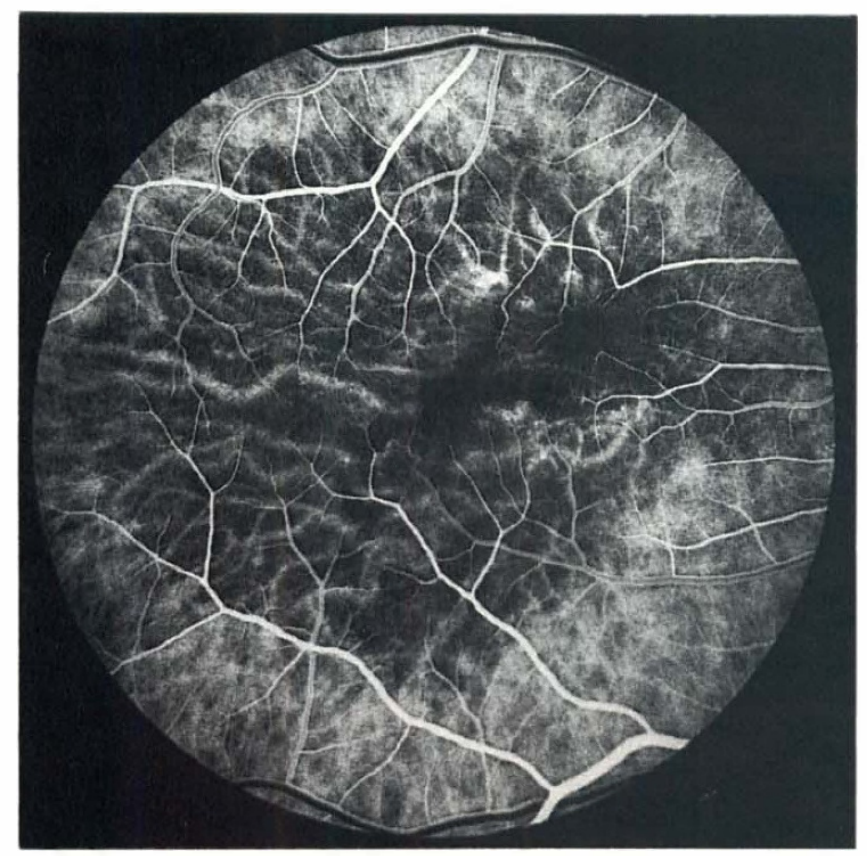

(b)

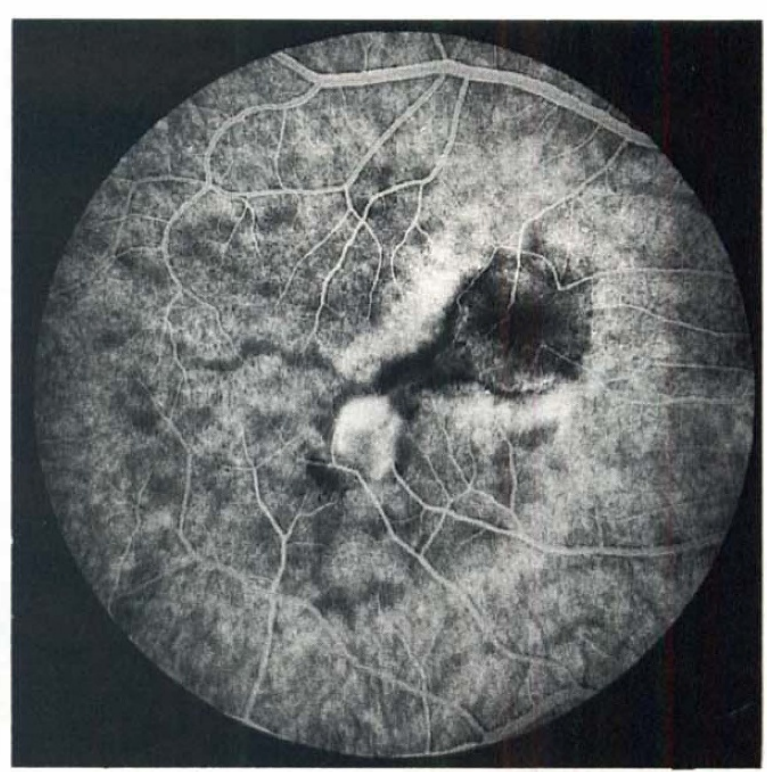

(c)

Fig. 12. Sorsby's fundus dystrophy. (a) Drusen-like deposits are present along the vascular arcades. Fluorescein angiography of a relative shows slow filling of the central choroid $(b)$ and late subtle hyperfluorescence of the central region and choroidal neovascularisation (c).

were unilateral and confined to the lower segments of the fundus. This was complicated by rapidly progressive visual loss and an upper visual field defect (Fig. 5). The picture appears more suggestive of a juxtapapillary choroidal neovascularisation than of drusen.

The available information is insufficient to classify this disorder as hereditary. Because of the young age of the patients described, the possibility of an inherited dystrophy cannot be excluded.

\section{DOYNE'S FAMILIAL HONEYCOMB CHOROIDITIS}

Although Hutchinson and Tay first described the familial occurrence of colloid degeneration of the retina, ${ }^{6}$ Doyne in 1899 was the first to provide 
convincing evidence of autosomal dominant inheritance in four members of one family. ${ }^{9}$ In 1910, he completed the description of the first pedigree and reported another family of four. ${ }^{10}$ Doyne believed that the lesions were due to an exudate in the choroid and therefore called the condition honeycomb choroiditis. Shortly thereafter, Treacher Colins ${ }^{18}$ showed that the choroid was essentially normal and that the white spots represented nodular thickening of Bruch's membrane.

The following is a summary of Doyne's observations of the condition: 'The disorder may appear in early adult life but much more commonly occurs later (at about 40 years of age). It consists of circular white patches affecting the papillomacular area. These increase in size and number during middle age and lead to pigmentary disturbance. The spots present in a closely grouped, characteristic honeycomb-like pattern. In old age, the discrete outlines of the spots disappear, merging to form a more or less homogeneous atrophic area. When atrophy arises, there is a steady worsening of vision. Both eyes are involved and the condition is slowly progressive. It is hereditary, affecting several members of the same family in different generations.' Unfortunately there were no illustrations of the fundi in Doyne's publications.

Additional English pedigrees have been reported by Mould, ${ }^{19}$ and some of Doyne's original families were surveyed by Tree in $1937,{ }^{20}$ and later by Franceschetti, François and Babel. ${ }^{14}$ Thirty-eight years after the original description, Tree published illustrations of five of his patients in various stages of the disease (Figs. 6-8). In 1967 Pearce $^{21}$ studied 76 members of six English families with the disorder, three of which were descendants of Doyne's original families. He confirmed that Doyne's honeycomb degeneration was dominantly inherited. Non-English families have also been reported. ${ }^{22}$

We studied another family that also originated from Oxfordshire which closely resembled the families described by Doyne. A 65-year-old woman with a 15 year history of progressive loss of right eye vision was found to have large, partly isolated, partly confluent drusen in both maculae. They were also present nasal to the optic disc. In the right eye there was a circular area of atrophy in the fovea, within the area of drusen (Fig. 9). On fluorescein angiography, there was early fluorescence of the deposits and late bright staining. Her 38-year-old son had an 8 year history of poor vision in one eye and similar ophthalmoscopic findings.

\section{MALATTIA LEVANTINESE}

Klainguti first described three pedigrees with macular and peripapillary degeneration at the Swiss Ophthalmological Society in $1932 .{ }^{11}$ The disease was called Malattia levantinese because the affected families lived in the Levantine valley, which is in the northern part of the Tessin canton of Switzerland. Wagner and Klainguti, ${ }^{23}$ and then Forni and Babel, ${ }^{24}$ reported large pedigrees which confirmed that this disorder was dominantly inherited. As described, the disease was characterised by the bilateral and symmetrical appearance of a diffuse granite-like change in the perifoveolar region in teenagers which led to visible fundus deposits by the age of 20 years. The deposits consisted of yellowish round spots of variable size at the level of the retinal pigment epithelium which usually began between disc and fovea. They tended to merge later, forming a circle of extensive white plaques with irregular edges. Lesions were also present on the nasal side of the disc. Later in life, the retinal pigment epithelium and choriocapillaris in the central macula became atrophic and there was accompanying pigment migration.

We have examined six families with this dominantly inherited disorder. One family could trace its origin to the Levantine valley of Switzerland. The symptoms, age of onset and ophthalmoscopic appearance of the deposits in our cases are in accord with Franceschetti's description. Centrally, the deposits were very densely packed and formed an almost continuous mass. Peripheral radially oriented deposits of 'basal laminar drusen' type were present consistently in all six families (Fig. 10a). There was also pigmentation without evidence of geographic atrophy. Fluorescein angiography showed very early and prolonged fluorescence of the deposits which was partially masked by pigment epithelial changes (Fig. 10b). One patient had choroidal neovascularisation in one eye. The small radial drusen were not described in Franceschetti's paper although they are clearly visible in his drawings (Fig. 11).

\section{SORSBY'S FUNDUS DYSTROPHY}

This dominantly inherited dystrophy originally described by Sorsby has been well characterised. ${ }^{25}$ In some patients a confluent yellow deposit at the level of the retinal pigment epithelium is associated with the subsequent development of geographic atrophy or choroidal neovascularisation. ${ }^{26,27}$ In others, the confluent thickening of Bruch's membrane may be difficult to identify by ophthalmoscopy, and the most obvious change is drusen-like deposits seen along the arcades and nasal to the optic disc rather than at the central macula (Fig. 12a). The diffuse nature of the change is revealed by fluorescein angiography (Fig. 12b, c). Drusen centred over the fovea are not a frequent finding in this disorder, making the distinction between Sorsby's fundus dystrophy and other forms of age- 
related and genetically determined drusen relatively straightforward.

\section{COMMENT}

Historically, the diagnosis of dominantly inherited drusen has often been made in those patients in whom the drusen appear at a relatively early age. Usually this is recognised after the age of 20 years but drusen have been described as early as age 12 and 14 years in brothers and in a girl aged 8 years. ${ }^{12,13}$ Strictly speaking, the term dominant drusen should be applied only to patients in families in which successive generations are involved and both males and females are affected. Using these criteria, the terms Hutchinson-Tay and HolthouseBatten choroiditis should no longer be considered synonymous with dominantly inherited drusen, as there is insufficient evidence that they represent genetically determined disorders. By contrast in Doyne's honeycomb dystrophy, Malattia levantinese and Sorsby's fundus dystrophy there is good evidence of dominant inheritance.

The view that the various manifestations of drusen of the posterior pole, including those in the elderly, represent the same inherited disorder has been popular in recent decades., ${ }^{4,13,14,23,28}$ Deutman believed that intra-familial variability in expression was responsible for the different funduscopic characteristics of dominantly inherited drusen of Bruch's membrane. ${ }^{13}$ Gass implied that all patients with macular drusen, whether young or elderly, have the same heredo-degenerative disease, which rarely causes significant visual loss prior to the sixth or seventh decades of life. ${ }^{4,28}$ That there may be a genetic predisposition to age-related macular disease is supported by a case-control study undertaken by Hyman and colleagues, ${ }^{29}$ a report by François and Deweer in $1952,{ }^{30}$ and a recent studies of cousins and of siblings and spouses of patients with age-related macular disease. ${ }^{31-33}$ If one were to adopt the view that drusen are all a manifestation of a single disease, the different ophthalmoscopic appearances of 'hyaline degeneration' of the posterior pole would be inconsequential, and the various eponyms which have been associated with these changes would have little value.

Evidence that there may be genetic determination of age-related macular disease does not prove that this represents the same disease entity as drusen which are clearly autosomal dominant in inheritance with high penetrance. Furthermore, the constancy in expression in Malattia levantinese of a phenotype which differs from that occurring in Doyne's honeycomb dystrophy implies that at least these two entities represent different genetically determined disorders. Small discrete drusen in the peripheral macula with a typical radial orientation and distribution is a consistent ophthalmoscopic feature in certain families, and characterises Malattia levantinese. These drusen were peripheral to larger confluent drusen, were always brightly fluorescent and appeared more numerous on fluorescein angiography than clinically. They have the clinical and angiographic ${ }^{4,24,28,30,34}$ appearance of 'basal laminar drusen' as described by Gass. ${ }^{4,35}$ Some of the cases described by Gass had a radial distribution ${ }^{4}$ and some did not, ${ }^{4,35}$ but none had a family history of eye disease. By contrast, none of Doyne's original families or their descendants were noted to have radially oriented basal laminar drusen. Further evidence of the differences between the conditions can be derived from histopathological studies. One was undertaken by Dusek and colleagues. $^{36,37}$ Although they did not make the distinction between Malattia levantinese and honeycomb dystrophy, the fundus photographs clearly illustrate the features of the former. The small drusen are shown to be continuous with, or internal to, the basement membrane of the retinal pigment epithelium. In Doyne's honeycomb dystrophy the drusen are external to the basement membrane, and occupy most of the thickness of Bruch's membrane. ${ }^{18} \mathrm{On}$ this basis, Doyne's honeycomb dystrophy appears most homologous with age-related change. On the basis of the presence of radial basal laminar drusen, several families reported in the literature to have a Doyne'stype 'colloid degeneration' might be more properly described as having Malattia levantinese. ${ }^{38,39}$ It is evident that Sorsby's fundus dystrophy is different from both Malattia levantinese and honeycomb dystrophy in the distribution of drusen, and the profound and even thickening of the inner portion of Bruch's membrane. ${ }^{40}$

Although incomplete, the accumulated evidence suggests that dominantly inherited drusen syndromes represent a group of disorders which can be differentiated from one another by clinical and ultrastructural criteria. This heterogeneity could be confirmed by further study of these families coupled with the emerging tools of molecular genetics.

This study was supported by grants from the Wellcome Trust, the Medical Research Council of the UK, and the National R.P. Foundation. B. P. was supported by the Fonds National Suisse pour la Recherche Scientifique, the Holderbank and the Janggen-Poehn Stiftung.

Key words: Dominant drusen, Doyne's honeycomb familial choroiditis, Holthouse-Batten chorioretinitis, Hutchinson-Tay choroiditis, Malattia levantinese.

\section{REFERENCES}

1. Wedl C. Rudiments of pathological history. London: George Busk, 1854:282.

2. Donders FC. Beitrage zur pathologischen Anatomie des Auges. Graefes Arch Ophthalmol 1855;1:106-18.

3. Deutmann AF. The hereditary dystrophies of the 
posterior pole of the eye. Assen, The Netherlands: van Gorcum, 1971:367-99.

4. Gass JDM. Stereoscopic atlas of macular diseases. St Louis: CV Mosby, 1987:60-97.

5. Jost BF. Dominantly inherited drusen. In: Newsome DA, editor. Retinal dystrophies and degenerations. New York: Raven Press, 1988:105-13.

6. Hutchinson J, Tay W. Symmetrical central chorioretinal disease occurring in senile persons. $\mathrm{R}$ London Ophthalmol Hosp Rep 1875;8:231-44.

7. Juler H. Guttata choroiditis. Trans Ophthalmol Soc UK 1893;13:143.

8. Holthouse EH, Batten RD. A case of superficial chorioretinitis of peculiar form and doubtful causation. Trans Ophthalmol Soc UK 1897;17:62-3.

9. Doyne RW. Peculiar condition of choroiditis occurring in several members of the same family. Trans Ophthalmol Soc UK 1899;19:71.

10. Doyne RW. A note on family choroiditis. Trans Ophthalmol Soc UK 1910;30:93-5.

11. Klainguti R. Die Tapeto-retinal Degeneration im Kanton Tessin. Klin Monatsbl Augenheilkd 1932;89: 253-4.

12. Evans PJ. Five cases of familial retinal abiotrophy. Trans Ophthalmol Soc UK 1950;70:96.

13. Deutman AF, Jansen LM. Dominantly inherited drusen of Bruch's membrane. Br J Ophthalmol 1970; $54: 373-82$.

14. Franceschetti A, François J, Babel J. Les hérédodégénérescence chorio-rétiniennes. Vol 1. Paris: Masson, 1963:494-515.

15. Clarke E. Tay's 'guttata choroiditis'. Proc R Soc Med 1932;25:59-60.

16. Bickerton RE. A peculiar form of affection of the choroid. Trans Ophthalmol Soc UK 1900;20:93-5.

17. Blair C. An unusual form of choroiditis. Trans Ophthalmol Soc UK 1901;21:68-70.

18. Treacher Collins E. A pathological report upon a case of Doyne's choroiditis ('honeycomb' or 'family' choroiditis). Ophthalmoscope 1913;11:537-8.

19. Mould GT. Family choroiditis. Trans Ophthalmol Soc UK 1910;30:189-90.

20. Tree M. Familial hyaline dystrophy in the fundus oculi or Doyne's family honeycomb choroiditis. $\mathrm{Br} \mathrm{J}$ Ophthalmol 1937;21:65-91.

21. Pearce WG. Doyne's honeycomb retinal degeneration: clinical and genetic features. Br J Ophthalmol 1968; 52:73-8.

22. Alper MG, Alfano JA. Honeycomb colloid degeneration of the retina. Arch Ophthalmol 1953;49:392-9.

23. Wagner $H$, Klainguti $R$. Heredodegeneration der Papillen und Maculagegend, beobachtet im Kanton Tessin (Malattia Levantinese). (Ges der Aerzte in Zurich, 21-1-1943.) Schweiz Med Wochenschr 1944; 74:197.

24. Forni S, Babel J. Etude clinique et histologique de la
Malattia levantinese: affection appartenant au groupe des dégénérescences hyalines du pole posterieur. Ophthalmologica 1962;313-22.

25. Sorsby A, Mason ME, Gardener A. A fundus dystrophy with unusual features. $\mathrm{Br} \mathrm{J}$ Ophthalmol 1949;33:67-97.

26. Polkinghorne PJ, Capon MRC, Berninger T, Lyness AL, Sehmi K, Bird AC. Sorsby's fundus dystrophy: a clinical study. Ophthalmology 1989;96:1763-8.

27. Steinmetz R, Polkinghorne PC, Fizke FW, Kemp CM, Bird AC. Abnormal dark adaptation and rhodopsin kinetics in Sorsby's fundus dystrophy. Invest Ophthalmol Vis Sci 1992;33:1633-6.

28. Gass JDM. Drusen and disciform macular detachment and degeneration. Arch Ophthalmol 1973;90:206-17.

29. Hyman LG, Lilienfeld AM, Ferris FL, Fine SL. Senile macular degeneration: a case-control study. Am J Epidemiol 1983;118:213-27.

30. François J, Deweer JP. Dégénérescence maculaire sénile et hérédité. Ann Occulist 1952;185:136-54.

31. Piguet B, Wells JA, Palmvang IB, Wormald $R$, Chisholm IH, Bird AC. Age-related Bruch's membrane change: a clinical study of the relative role of heredity and environment. $\mathrm{Br} \mathrm{J}$ Ophthalmol 1993;77:400-3.

32. Heiba IM, Elston RC, Klein BEK, Klein R. Sibling correlations and segregation analysis of age-related maculopathy: the Beaver Dam study. Genet Epidemiol 1994;11:51-67.

33. Klein ML, Mauldin WM, Stoumbos VD. Hereditary and age-related macular degeneration: observations in monozygotic twins. Arch Ophthalmol 1994;112:932-8.

34. Streicher T, Krcméry K. Das fluoreszenzangiographische Bild der hereditären Drusen. Klin Monatsbl Augenheilkd 1976;169:22-30.

35. Gass JDM, Jallow S, Davis B. Adult vitelliform macular detachment occurring in patients with basal laminar drusen. Am J Ophthalmol 1985;99:445-59.

36. Streicher T, Schmidt K, Dusek J. Hereditäre Drusen der Bruchschen Membran. I. Klinische und lichtmikroskopische Beobachtungen. Klin Monatsbl Augenheilkd 1982;181:27-31.

37. Dusek J, Streicher T, Schmidt K. Hereditäre Drusen der Bruchschen Membran. II. Untersuchung von Semidünnschnitten und electronmikroskopischen Ergebnissen. Klin Monatsbl Augenheilkd 1982; $181: 79-83$

38. Pajtás J. A case of Doyne's honeycomb choroiditis. Ceskoslov Oftal 1950;6:282-6.

39. Pajtás J. Honigwabenähnliche Hyalindegeneration der Netzhaut als nosologische Einheit. Ophthalmologica 1957;134:101-11.

40. Capon M, Marshall J, Krafft JI, Alexander RA, Hiscott PS, Bird AC. Sorsby's fundus dystrophy: a light and electron microscopic study. Ophthalmology 1989; 96:1769-77. 